\title{
Different Radial Growth Responses to Climate Change of Three Dominant Conifer Species in Temperate Forest, Northeastern China
}

\author{
Hui Wang ${ }^{1}$, Yangcui Ning ${ }^{1}$, Chunlan Liu' ${ }^{1}$, Peng $X u^{2}$ and Wentao Zhang ${ }^{3,4 *}$ \\ ${ }^{1}$ Beijing Municipal Research Institute of Environmental Protection, Beijing, China, ${ }^{2}$ School of Geography and Planning, Sun \\ Yat-sen University, Guangzhou, China, ${ }^{3}$ Qingdao Institute of Humanities and Social Sciences, Shandong University, \\ Qingdao, China, ${ }^{4}$ Center for Ecosystem Products Value Realization, Yellow River National Strategic Research Institute, \\ Shandong University, Qingdao, China
}

OPEN ACCESS

Edited by:

Jian Tao,

Shandong Institute of Business and Technology, China

Reviewed by:

Liang Jiao,

Northwest Normal University, China

Zhudeng Wei,

Nanjing University of Information and Science Technology, China

Yuan Jiang,

Beijing Normal University, China

${ }^{*}$ Correspondence: Wentao Zhang

zhangwt@sdu.edu.cn

Specialty section:

This article was submitted to Temperate and Boreal Forests,

a section of the journal

Frontiers in Forests and Global

Change

Received: 23 November 2021 Accepted: 07 December 2021

Published: 13 January 2022

Citation:

Wang $H$, Ning Y, Liu C, Xu P and Zhang W (2022) Different Radial

Growth Responses to Climate Change of Three Dominant Conifer Species in Temperate Forest, Northeastern China.

Front. For. Glob. Change 4:820800 doi: 10.3389/ffgc.2021.820800
We conducted dendroclimatological study on three dominant conifer tree species, Pinus koraiensis, Larix olgensis, and Picea jezoensis, in northeastern China for a better understanding of climate change impacts on temperate forest growth, by discussing the radial growth relationships of these tree species and projecting their radial growth trends under the future climate change scenarios. Based on the tree-ring samples collected from the upper altitude of Changbai Mountain, ring width chronologies were built to examine the growth relationships, and regression equations were established to project the future growth of the species under future climate change projected by the five general circulation models (GCMs) and four representative concentration pathway $(\mathrm{RCP})$ scenarios. Although both temperature and precipitation showed varying degrees of relationships with growth of these three tree species, the limiting climate factors were species-specific. The tree-ring growth of $P$. koraiensis was limited by the summer temperature and precipitation at the end of growth, namely, significant positive correlations with the current July temperature and the previous September precipitation. Growth of $L$. olgensis was limited by the temperature before growing season, for its chronology was negatively correlated with the current February and previous December temperature $(p<0.05)$. The climatic conditions before and after growing season seemed to be the limiting factors of $P$. jezoensis growth, which was negatively correlated with the current February to April temperature and the current September temperature $(p<0.05)$, and positively correlated with the current August precipitation $(p<0.05)$. Under the gradual increasing of temperature predicted by the five GCMs and four RCP scenarios, the radial growth of $P$. Koraiensis will relatively increase, while that of $L$. olgensis and $P$. jezoensis will relatively decrease comparing to the base-line period (1981-2010). The specific growth-climate relationships and the future growth trends are species dependent. $P$. Koraiensis was the more suitable tree species for the forestation to maintain the sustainable forest in Changbai Mountain.

Keywords: climate change, radial growth, dendroclimatology, Changbai Mountain, temperate forest 


\section{INTRODUCTION}

Global warming and its influences on the structure, function, and growth of the forest ecosystem have been observed and recognized (Lindner et al., 2010; IPCC, 2013; Rahman et al., 2017; Russell and Parton, 2020). The annual mean temperature in China has increased 0.9 to $1.5^{\circ} \mathrm{C}$ during the last 100 years (19092011) larger than the global average (Editorial Commission of Northeast Regional Climate Change Assessment Report, 2013), and different climate models under different scenarios all predict that climate warming will continue in future in China (Xu et al., 2006; Xu et al., 2016; Zhang et al., 2017). A better understanding of how forest ecosystem in response to climate change is of great significance for maintaining productive and sustainable forest, and this requires more precise tree growth-climate relationships.

Tree-ring can be used as an important data source to study impacts of climate change on tree growth, for tree-ring recording the tree growth process and reflecting the effect of tree growth climate conditions. In addition, tree-ring material has many advantages, such as a wide range distribution, high resolution, accurate dating, and easy access to multiple copies (Hughes, 2002; Cook et al., 2004; Breitenmoser et al., 2014). Accordingly, many studies on tree growth-climate relationships have been widely carried out by dendroclimatological method using this proxy data (Fritts, 1976; Lebourgeois et al., 2012; Housset et al., 2018; Zhang et al., 2018).

Compared with boreal forests, temperate forests are characterized by high precipitation, high humidity, and more deciduous tree species, indicating more complex growth-climate relationships and potential growth trends under climate change (Castagneri et al., 2014; Han et al., 2019; Prislan et al., 2019; Wu et al., 2019). Some dendroecological studies were conducted on the radial growth of Pinus sylvestriformis, Picea jezoensis, and Pinus koraiensis in the temperate forest of Changbai Mountain, showing comprehensive influence of temperature and precipitation (Yu et al., 2016, 2021). If the global temperature continues to increase in the future, growth of $P$. jezoensis will undergo an adverse impact (Yu et al., 2021). At the same time, the climate conditions related to growing seasons have been found to be limiting factor for temperate forest growth usually, especially summer temperature (Castagneri et al., 2014; Chen et al., 2017; Wu et al., 2019), spring, and winter temperatures before growing season (Pederson et al., 2004; Yan et al., 2017; Prislan et al., 2019). Above all, although many studies have already addressed the unstable relationships between radial growth and climate, the climatic responses still need to dig deeper.

Changbai Mountain in Northeastern China is covered by a large area of undisturbed temperate forest and characterized by a vertical zonation of forest ecosystems along the altitudinal gradient (Editorial Committee for Forestry of Jilin, 1988). P. koraiensis, Larix olgensis, and P. jezoensis are its three dominant conifer tree species. The climate warming in Changbai Mountain has been obvious since the 1950s (Wang et al., 2010; Jia et al., 2017; Jiang et al., 2019). Under this background, many studies were carried out in this region to discuss the influence of climate change on the forest ecosystem using dendroclimatological method. Some revealed that elevation differences exerted a strong influence on the growth-climate relationships for the individual conifer tree species (Wang et al., 2013; Shen et al., 2016; Wang H. et al., 2017; Wang X. C. et al., 2017), but the difference among the tree species growth-climate relationships was rarely compared, which is also important for examining the regional growthclimate precisely and thoroughly.

This study chose the three main conifer tree species of P. koraiensis, L. olgensis, and P. jezoensis in Changbai Mountain to discuss the radial growth relationships of the three tree species and to project their radial growth trends under the future climate change scenarios.

\section{MATERIALS AND METHODS}

\section{Study Area and Field Sampling}

The study area is located on the north slope of the Changbai Mountain Natural Reserve in northeastern China (Figure 1). This area is characterized by a temperate continental monsoon climate. The meteorological data of the Donggang and Erdao stations (data from the National Meteorological Information Center of China) showed that the mean annual temperature was $3.2^{\circ} \mathrm{C}$, with a mean temperature of $-16.8^{\circ} \mathrm{C}$ in January and $20.1^{\circ} \mathrm{C}$ in July during the period 1958-2007 (Figure 2). The mean annual precipitation was $746.4 \mathrm{~mm}$, and mainly occurred from May to September. The vegetation in this area has the characteristic of vertical zonality. Korean pine and broad-leaved mixed forest are located from 500 to $1,100 \mathrm{~m}$. A spruce-fir forest continues from 1,100 to $1,800 \mathrm{~m}$. The soil in the coniferous forest zone is mountainous brown forest soil (Editorial Committee for Forestry of Jilin, 1988).

Tree-ring cores of $P$. koraiensis, L. olgensis, and P. jezoensis were all sampled at their upper altitudinal limit in the mountain dark coniferous forest zone distributed from 1,100 to $1,800 \mathrm{~m}$ a.s.l. For each site, approximately 20-30 trees were selected and two cores were sampled per tree.

\section{Chronology Development}

Cores were dried and sanded to produce clearly visible tree-ring boundaries, and then cross-dated (Stokes and Smiley, 1968). The ring width was measured using the LINTAB-station (Frank Rinn, Heidelberg, Germany) at a $0.01 \mathrm{~mm}$ resolution. The COFECHA program (Holmes, 1983) was used to check the quality of crossdating and measurements.

The tree-ring chronologies was developed using the ARSTAN program (Cook, 1985). A cubic smoothing spline with 67\% of the series length was used to remove the age-related growth trends of raw ring-width chronologies. The resulting ratio series were then computed as a biweight robust mean of the detrended and standardized individual series (Cook et al., 1990). To show the strength of common signals in the chronologies, a within-chronology common interval analysis for each chronology was performed. The statistical quality of each chronology was measured using several coefficients commonly used in dendrochronology. We calculated the standard deviation (SD) to estimate the variability of ring width series, and the mean sensitivity (MS) to indicate the relative changes in ring width 


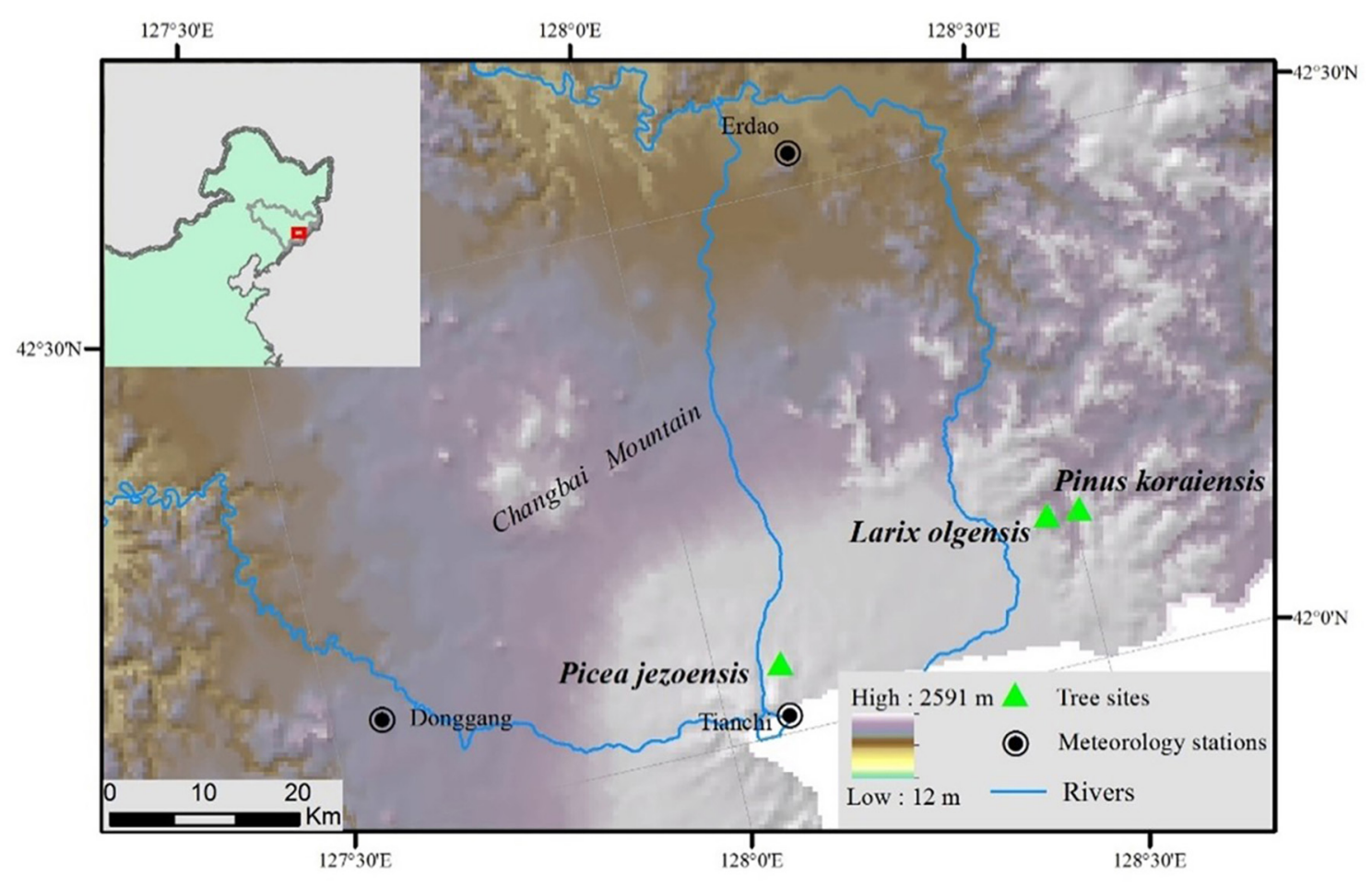

FIGURE 1 | Locations of sample sites and meteorological stations in the study area.

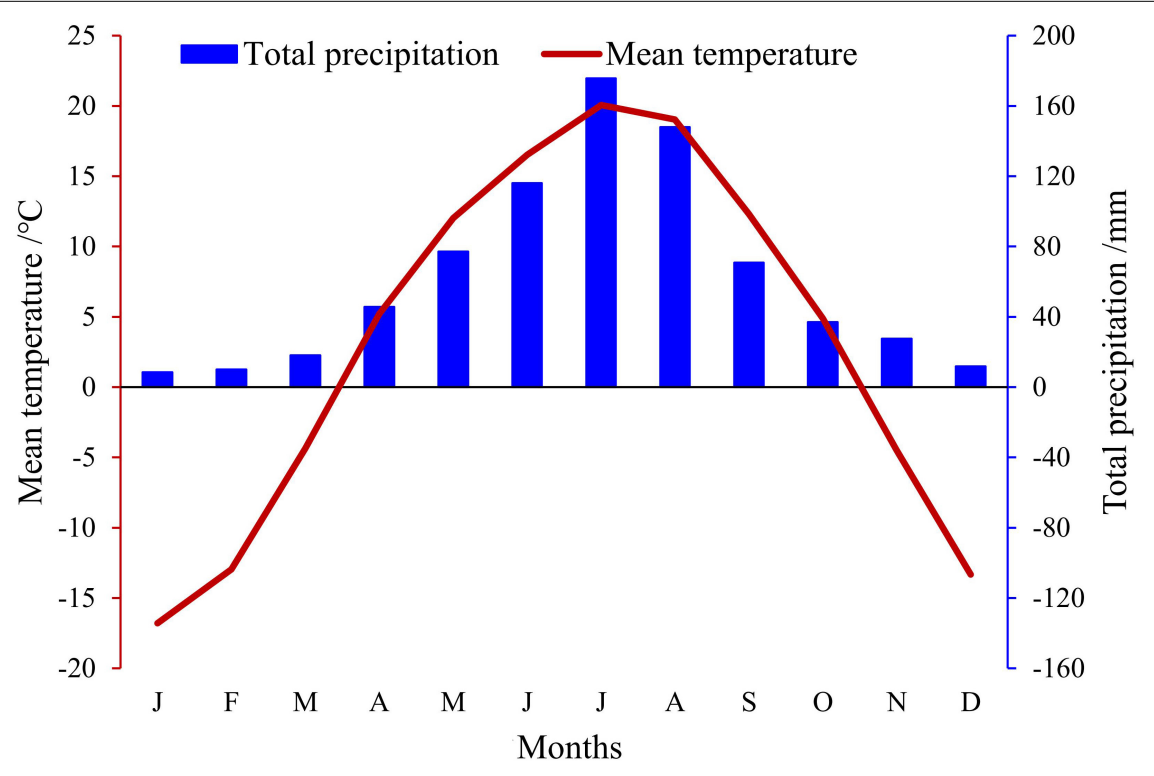

FIGURE 2 | Monthly total precipitation and mean temperature at Changbai Mountain based on the Donggang and Erdao meteorological stations (1958-2007).

index variance between consecutive years, and the first-order autocorrelation $(\mathrm{AC} 1)$ to measure the influence of the previous year's growth on the current ring, and the mean correlation between trees (R) and the first principal component (PC1) to indicate the common signal strength. The expressed population signal (EPS) was also calculated to indicate the chronology confidence level (Briffa and Jones, 1990), and a threshold value of 0.85 is often used to evaluate the useful and valid time span of the final chronologies (Wigley et al., 1984).

Gleichläufigkeit index was calculated to measure level of agreement between consecutive ring width slopes. The degree of similarity between two series based on the 
positive (upward) or negative (downward) trends of each width was expressed as a percentage of the number of intervals (Schweingruber, 1988; Schweingruber et al., 1993). Gleichläufigkeit index (GLK) was computed according to the formula (Feliksik and Wilczyński, 2009):

$$
G L K=100 \cdot m \cdot(n-1)^{-1}[\%]
$$

where $m$ is the number of concordant (as to the direction) chronology sections, and $n$ is the length of the period under comparison in years.

Pearson correlation coefficient was calculated to measure the consistence of variation amplitude correlated with the sensitivity of the chronology.

\section{Growth-Climate Relationships}

There are three meteorological stations named Erdao (591 m a.s.l.), Donggang (774 $\mathrm{m}$ a.s.l.), and Tianchi (2623 $\mathrm{m}$ a.s.l.) in the study area (Figure 1). Among them, Tianchi station data were not used in our study because winter observations have been terminated since 1989. The monthly temperature and precipitation correlation coefficients at Erdao and Donggang from 1958 to 2007 were $0.95(p<0.01)$ and $0.79(p<0.01)$, respectively. Therefore, we averaged the recorded climate data from the Erdao and Donggang to improve the regional representation when used to analysis the growth-climate relationships.

Pearson correlation coefficients between the tree-ring width and monthly mean temperature and total precipitation were calculated between 1958 and 2007 to identify the growth-climate relationships (Fritts, 1974) throughout 13 months from the previous September to the current September.

\section{Future Projection of the Radial Growth Trends}

The future climatological data were projected by five general circulation models (GCMs) (HadGEM2-ES, IPSL-CM5A-LR, GFDL-ESM2M, MIROC-ESMCHEM, and NorESM1-M) (Yin et al., 2015) and four representative concentration pathway (RCPs) (RCP2.6, RCP4.5, RCP6.0, and RCP8.5) scenarios (Moss et al., 2010) used in the Intergovernmental Panel on Climate Change (IPCC) Fifth Assessment Report. To evaluate the simulation capacity of the models for the study area, Pearson correlation coefficients between the observed and the simulated monthly temperature and precipitation were calculated during 1981-2010. To reduce uncertainty in GCMs performance, an average of the five GCMs under each emission scenario was used in this study. The future projection was predicted between 2011 and 2100 .

The regression equations between ring width and climatic factors were established by stepwise regression method to calculate tree-ring index. The regression equations, passing the significance test at 0.005 levels and explaining variances all over 20\%, were used for the growth projections. Sum of square error (SSE) and mean squared error (RMSE) were calculated to measure the fitting effect of the equations. The relative variation rate (RVI) was used to evaluate the impacts of future climate change on the radial growth of the three tree species.

$$
\mathrm{RVI}=\frac{\mathbf{Y}(\mathbf{X}+\Delta \mathbf{X})-\mathbf{Y}(\mathbf{X})}{Y(X)} \times 100 \%
$$

RVI: the variation rate of tree-ring index; Y: the tree-ring width index; $\mathrm{X}$ : the monthly total precipitation and mean temperature; $\triangle \mathbf{X}$ : the variable quantity of monthly total precipitation and mean temperature.

\section{RESULTS}

\section{Chronology Characteristics}

Three ring-width chronologies were built for the three conifer tree species. Table 1 shows the statistical characteristics of the three chronologies. $P$. jezoensis had the higher statistical indices than the other two tree species, except for L. olgensis' SD. $P$. koraiensis had the lowest statistics of the three tree species. The EPS of the three chronologies all exceeded the recommended threshold of 0.85; according to Wigley et al. (1984), they were all suitable for dendroclimatological studies.

The annual and 5-year moving averaged ring width indices revealed the correlations among chronologies in high-frequency and low-frequency, respectively (Figure 3). They showed the similar variation in 1990s, circa 1885 to 1905 , but they were different in circa 1975, circa 1930 to 1935 . Gleichläufigkeit indices of the three chronologies were 57, 53, and 53\%, all greater than $50 \%$ over 200 years. The $P$. koraiensis chronologies showed better relationships with the other two chronologies $(R=0.22$ and 0.28 , respectively) than the relationship between $L$. olgensis and $P$. jezoensis chronologies $(R=0.09)$ (Table 2).

\section{Relationships Between Tree-Ring Chronologies and Climatic Factors}

The growth-climate relationships were different for the three tree species (Figure 4). P. koraiensis chronology was significantly

TABLE 1 | The sampling site information, the standard chronology statistics, and

\begin{tabular}{|c|c|c|c|}
\hline Site no. & Site 1 & Site 2 & Site 3 \\
\hline Tree species & Pinus koraiensis & Larix olgensis & Picea jezoensis \\
\hline Latitude (N) & $42.14^{\circ}$ & $42.14^{\circ}$ & $42.07^{\circ}$ \\
\hline Longitude (E) & $128.47^{\circ}$ & $128.51^{\circ}$ & $128.09^{\circ}$ \\
\hline Elevation (m a.s.l) & 1258 & 1258 & 1770 \\
\hline Tree/Core & $29 / 58$ & $22 / 44$ & $21 / 41$ \\
\hline MS & 0.115 & 0.150 & 0.121 \\
\hline SD & 0.146 & 0.206 & 0.198 \\
\hline AC1 & 0.534 & 0.590 & 0.705 \\
\hline $\mathrm{R}$ & 0.356 & 0.397 & 0.410 \\
\hline EPS & 0.958 & 0.959 & 0.965 \\
\hline PC1 (\%) & 37.6 & 42 & 43.7 \\
\hline
\end{tabular}
the results of the common period analysis.

MS indicates the mean sensitivity, $S D$ the standard deviation, AC1 the firstorder autocorrelation, $R$ the mean correlation between trees, EPS the expressed population signal, and PC1 the first principal component. 


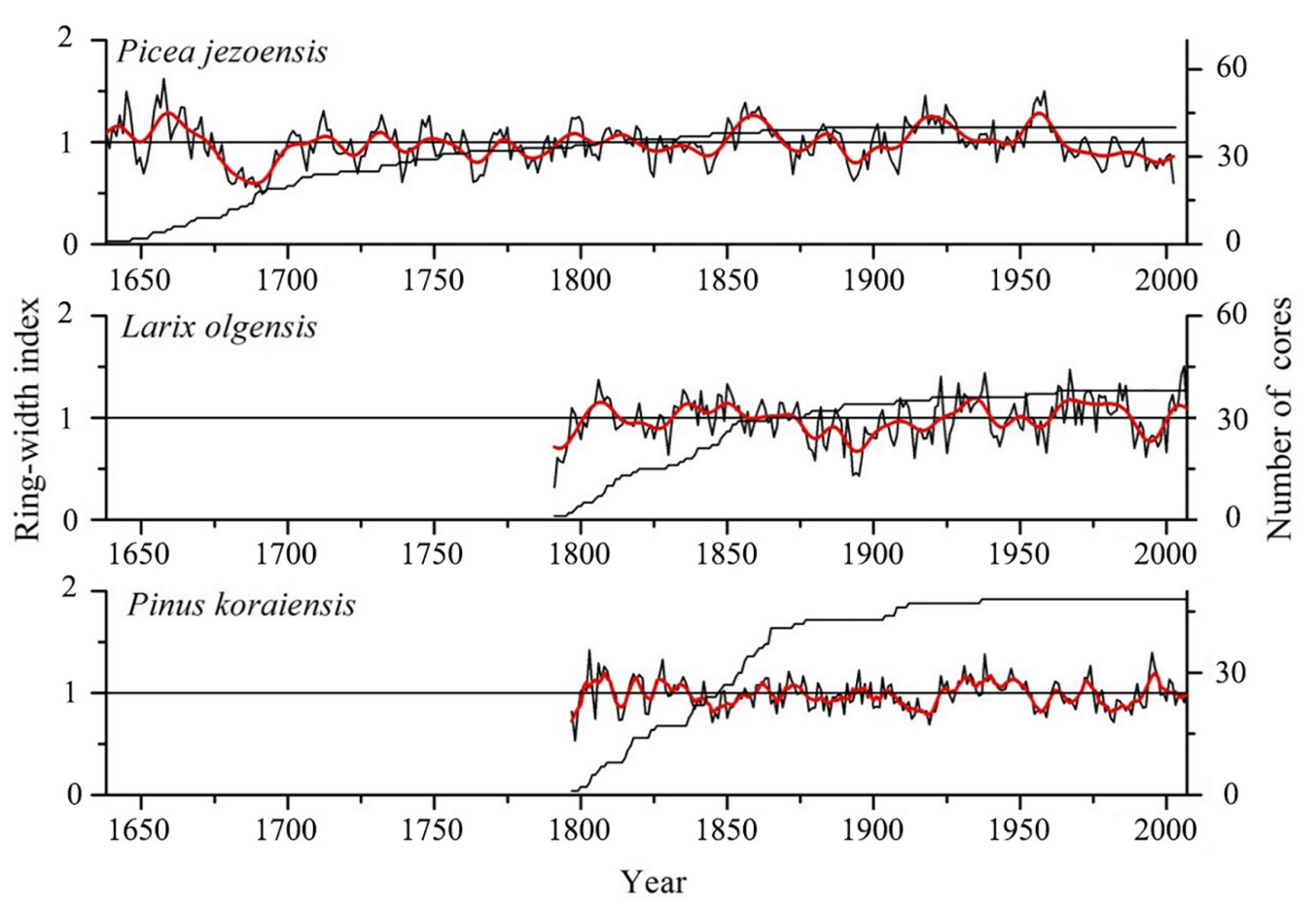

FIGURE 3 | Ring-width index series of the chronologies (left $Y$-axis) and numbers of tree-ring sample cores used in the chronology development (right $Y$-axis). The red lines represent the 5-year moving averages.

and positively correlated with temperature in the current July and precipitation in the previous September. Different from P. koraiensis, L. olgensis ring width index chronology was negatively and significantly correlated with temperature in the current February and the previous December. P. jezoensis was negatively correlated with the temperature in the current months especially with February to April and September (all $p<0.05$ ), and it was positively correlated with the current August precipitation significantly.

\section{The Future Radial Growth Trends Under the Projected Climate}

Figure 5 shows the future climate change predicted by five GCMs under four emission scenarios. During 1981-2010, the correlation coefficient between the observation and the simulated monthly temperature and precipitation was $0.987(p<0.001)$ and $0.721(p<0.001)$, respectively. The annual average temperature increased gradually for all RCPs, and the temperature in 2099

TABLE 2 | Gleichläufigkeit indices (GLK) and Pearson correlation coefficients (R) among the three chronologies.

\begin{tabular}{|c|c|c|c|c|}
\hline & \multicolumn{2}{|c|}{ Pinus koraiensis } & \multicolumn{2}{|c|}{ Larix olgensis } \\
\hline & GLK & $\mathbf{R}$ & GLK & $\mathbf{R}$ \\
\hline Larix olgensis & $57 \%^{*}$ & $0.22^{*}$ & & \\
\hline Picea jezoensis & $53 \%$ & $0.28^{*}$ & $53 \%$ & 0.09 \\
\hline
\end{tabular}

* refers to the significance at 0.05 level. is $1.4,2.1,3.5$, and $6.3^{\circ} \mathrm{C}$ higher than the temperature in 2011, respectively, for RCP2.6, RCP4.5, RCP6.0, and RCP8.5, respectively (Figure 5A). The annual total precipitation also had a rising trend, increased about $10 \mathrm{~mm}$ from 2011 to 2100 for the individual RCPs (Figure 5B).

Three equations were chosen for prediction of the future radial growth (Table 3 ). They all passed the significance test at 0.005 levels and explained variances all over $20 \%$. The correlation coefficient between observed and the modeled tree-ring width index are $0.482(p<0.01), 0.761(p<0.01)$, and $0.533(p<0.01)$ for P. koraiensis, L. olgensis, and P. jezoensis, respectively. Under the future climate change scenarios, compared with the baseline term of 1981-2010, the annual ring width of $P$. koraiensis will increase by more than $20 \%$ in the three future periods (Table 4 ). The ring width of L. olgensis and $P$. jezoensis will decrease by more than 48 and $29 \%$ in the three future periods, respectively. As carbon intensity increased from low greenhouse gas emissions scenarios (RCP2.6) to high greenhouse gas emissions scenarios (RCP8.5), the variation magnitude will be enhanced for all the three tree species.

\section{DISCUSSION}

\section{Species-Specific Growth-Climate Relationships}

Pinus koraiensis, L. olgensis, and P. jezoensis chosen in this study were the three typical and representative conifer tree species of Changbai Mountain 


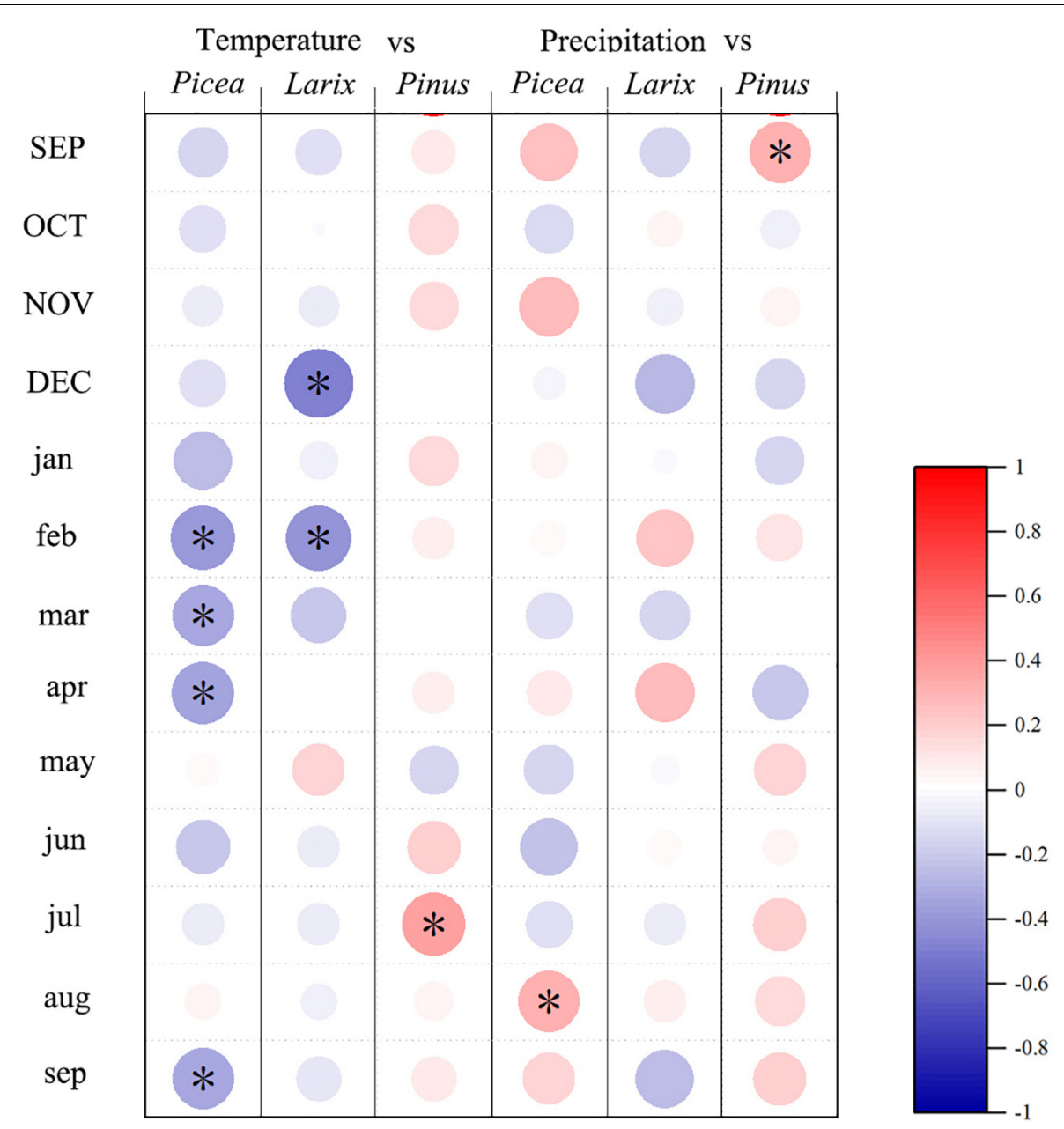

FIGURE 4 | Pearson correlation coefficients between monthly climatic factors and ring width indices for Pinus koraiensis, Larix olgensis, and Picea jezoensis. Sizes of the circles indicate the strengths of the correlation coefficients. The gradual change of color from blue to red indicates a gradual change of correlation from negative to positive. The capitalized months mean them from the past year, and the lowercase from the current year. The "*" indicated a significance $p<0.05$.

(Editorial Committee for Forestry of Jilin, 1988). The established chronologies had good statistical quality, suggesting they were suitable for dendroclimatological study. High Gleichläufigkeit indices illustrated the good overall similarity of width trends among the three chronologies, which can crossdate with each other. However, the correlation coefficients between the L. olgensis and $P$. jezoensis were weak, indicating that the amplitude of variation for the two chronologies had poor consistence (Shao et al., 2003). This may inform differences in the ecological information recorded by the chronologies, but the further identification of such information required a comparison of the chronologies with climate data (Wimmer and Grabner, 2000; Fonti and García-González, 2004).

According to the new climate regionalization scheme for China, Changbai Mountain belongs to the middle temperate humid climate zone located in northeastern China, where temperature is the main limiting factor for forest growth. However, further analyses showed that precipitation were the one of the limiting climate factors for the tree radial growth in Changbai Mountain as well. Due to the vertical zonality of Changbai Mountain, the microclimate (such as temperature, precipitation, and soil moisture) is different (Editorial Committee for Forestry of Jilin, 1988), which further leads to the influence of altitude on the radial growth-climate relationships for the individual tree species. In general, at low elevation site, the radial growth was positively correlated with the precipitation, while at the upper elevation, radial growth was significantly correlated with the temperature. This rule was applied to the main tree species in the region scale (Zhuang et al., 2017). On the other hand, some studies have also shown that differences in growth-climate relationships between tree species were more influential than those between sites ( $\mathrm{Yu}$ et al., 2011), which were consistent with the results reported by Graumlich (Graumilch, 1993), but differed from some other findings in northwest China, Picea crassifolia in Qilian Mountain for example (Liang et al., 2010).

Our study suggested that the three conifer tree species' radial growth was affected by both temperature and precipitation, 

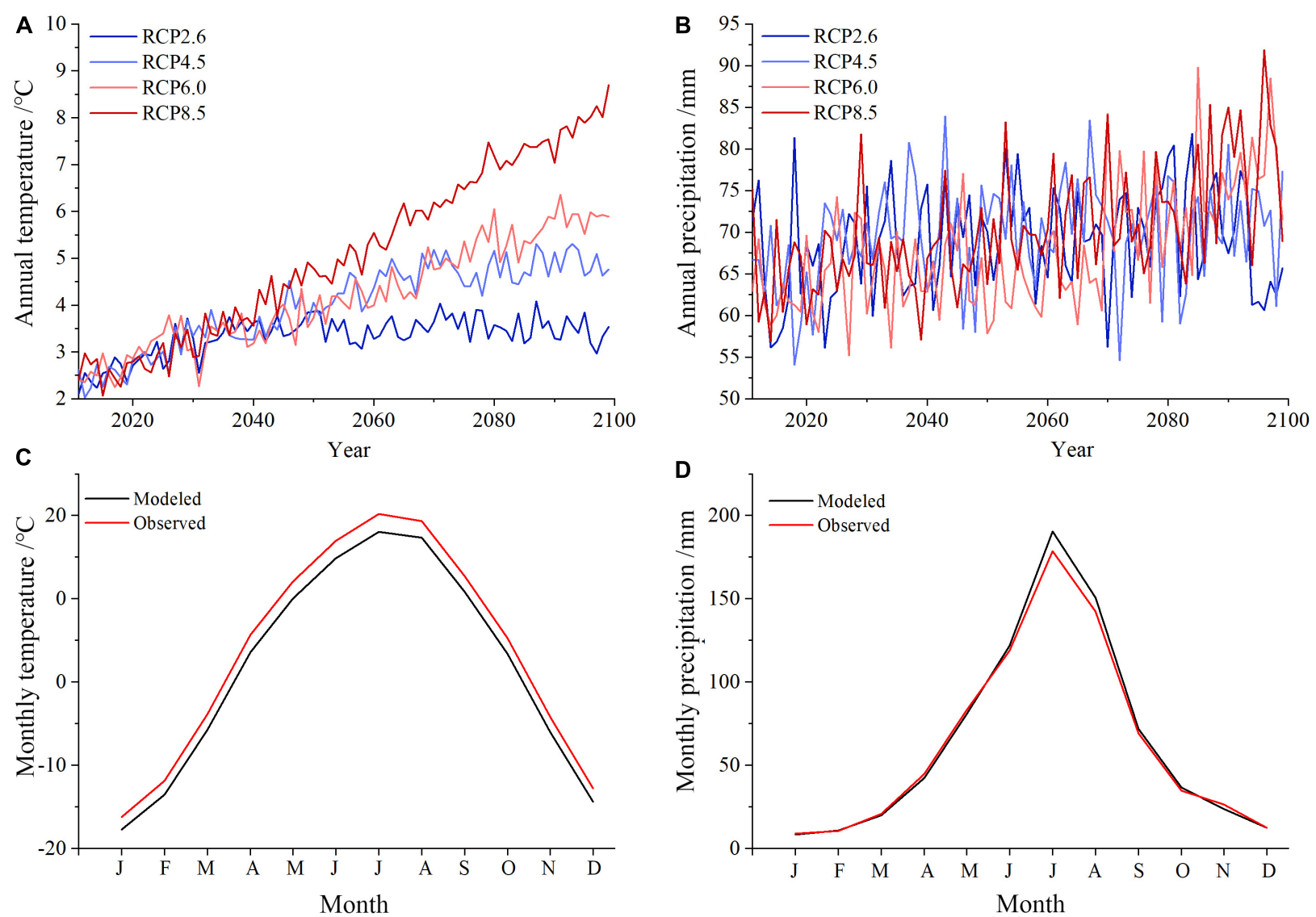

FIGURE 5 | Climate changes in (A) annual temperature and (B) annual precipitation during 2011-2100 relative to the baseline period for four RCPs. Modeled and observed averages of (C) monthly temperature and (D) monthly precipitation during 1981-2010.

and the specific responses of tree radial growth to climate were dependent on the species. The main difference was that $P$. Koraiensis radial growth was positively and significantly correlated with temperature, whereas L. olgensis and P. jezoensis radial growth were negatively and significantly correlated with temperature; these findings were confirmed by the other studies. With the detailed analysis, the current July temperature was the main climatic limiting factor for the growth of P. koraiensis, verified by Gao et al. (2018), because the decreasing temperature may lead to a delay of the onset of the growth period and the termination of growth before the end of the normal growing season. In addition, the previous September precipitation was another climatic limiting factor for the growth P. koraiensis, for that the concentrating period of precipitation was from

TABLE 3 | Statistics of equation for Pinus koraiensis, Larix olgensis, and Picea jezoensis.

\begin{tabular}{lcccccc}
\hline & $\boldsymbol{R}$ & $\boldsymbol{R}^{\mathbf{2}}$ & $\boldsymbol{F}$ & Sig. & SSE & $\boldsymbol{R M S E}$ \\
\hline Pinus koraiensis & 0.539 & 0.290 & 6.134 & 0.001 & 0.124 & 0.125 \\
Larix olgensis & 0.761 & 0.581 & 11.924 & 0.000 & 0.150 & 0.142 \\
Picea jezoensis & 0.482 & 0.232 & 6.343 & 0.004 & 0.179 & 0.172
\end{tabular}

May to September. Therefore, high precipitation in September was more important to the accumulation of soil moisture, which affected the growth of $P$. koraiensis in the next year. The radial growth of $L$. olgensis was negatively affected by the temperature in the current February and the previous December, while the radial growth of for $P$. jezoensis was negatively with temperature from February to April. Some other studies showed that the above negative correlations may be caused by the drought stress when the temperature rises for the high altitude growth of the conifer tree growth ( $\mathrm{Yu}$ et al., 2006; Li et al., 2011). The special geological conditions in Changbai Mountain lead to the thin soil layer and poor water storage capacity in high altitude areas. With the increase of temperature, the evapotranspiration of soil water and the transpiration of plants may accelerate to inhibit the tree growth, reduce leaf area, and then affect the photosynthetic characteristics of plants, which is most obvious in spring when drought stress is prone to occur.

\section{The Projected Future Radial Growth}

The future climate change in Changbai Mountain area was predicted by different climate models with different climate scenarios (Zeng et al., 2009; Wang et al., 2013; Yu et al., 2015), and 
TABLE 4 | RV values for the three periods based on tree-ring climate relationship.

\begin{tabular}{|c|c|c|c|c|c|c|c|c|c|c|c|c|}
\hline & \multicolumn{3}{|c|}{ RCP2.6 } & \multicolumn{3}{|c|}{ RCP4.5 } & \multicolumn{3}{|c|}{ RCP6.0 } & \multicolumn{3}{|c|}{ RCP8.5 } \\
\hline & 2020s & 2050s & 2080s & 2020s & 2050s & 2080s & 2020s & 2050s & 2080s & 2020s & 2050s & 2080s \\
\hline Pinus koraiensis & 22.33 & 28.37 & 26.8 & 20.97 & 31.81 & 37.88 & 23.7 & 34.85 & 47.41 & 27.59 & 43.59 & 63.29 \\
\hline Larix olgensis & -48.03 & -52.28 & -52.61 & -46.83 & -57.92 & -63.94 & -59.09 & -68.32 & -81.05 & -61.24 & -78.98 & -98.8 \\
\hline Picea jezoensis & -29.51 & -32.64 & -32.16 & -28.63 & -35.59 & -40.35 & -35.81 & -41.54 & -50.69 & -37.11 & -49.73 & -62.92 \\
\hline
\end{tabular}

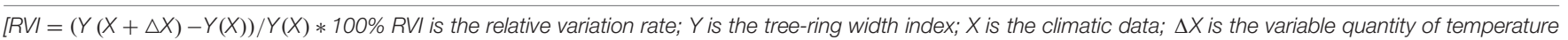
and precipitation]

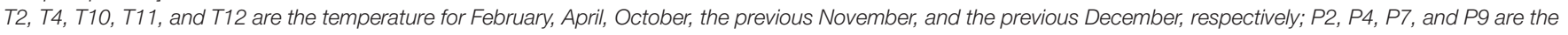
precipitation for February, April, July, and the previous September.

those studies all predicted temperature will increase gradually in future. However, the prediction results for precipitation are inconsistent, which indicated that the change of future precipitation is uncertain. GCMs have become the main tool in future climate change assessment and RCPs were used in IPCC Fifth Assessment Report to investigate the impact of greenhouse gasses on climate change (IPCC, 2013). They were proved to have good simulation abilities for local climate characteristics over China (Yin et al., 2015) and in Changbai Mountain (Yu et al., 2015; Wang et al., 2019).

Under the climate change scenarios, in the future (20112099), the temperature in Changbai Mountain will increase obviously, and the rates of increase are $0.14^{\circ} \mathrm{C} / 10$ a (RCP2.6), $0.21^{\circ} \mathrm{C} / 10$ a $(\mathrm{RCP} 4.5), 0.35^{\circ} \mathrm{C} / 10$ a $(\mathrm{RCP} 6.0)$, and $0.63^{\circ} \mathrm{C} / 10$ a (RCP8.5), which are generally consistent with those of the whole China (Yin et al., 2015). The different growth-climate relationships dependent on tree species caused the different future radial growth under future climate warming, and this finding was verified by other studies (Li et al., 2011; Zhuang et al., 2017). For $P$. koraiensis, the radial growth will increase greatly when the temperature rise. But for L. olgensis and P. jezoensis, the radial growth will relatively decrease with temperature increase in future. In detail, a warming growing season will benefit growth and distribution spread of $P$. koraiensis, while temperature increase before growing season will restrict the growth and survival of $L$. olgensis and $P$. jezoensis. If warming continues in the future, the distribution of $P$. koraiensis at high altitude will very likely expand; however, the range of $L$. olgensis and $P$. jezoensis will narrow for their decline in competitiveness. These dominant tree species shift may further lead to the changes of forest composition, structure, and the potential distribution area for the mountain dark coniferous forest where they distributed.

It should be noted that the above projections based on the growth-climate relationships and future climate change may be of some uncertainty. On the one hand, some uncertainties may exist in GCMs and RCPs. On the other hand, the other environmental and biological factors affecting tree growth also may change, bringing about the future growth change.

\section{CONCLUSION}

The radial growth of the three main conifer tree species of P. koraiensis, L. olgensis, and P. jezoensis, distributed at their upper altitudinal limit on the north slope of Changbai Mountain, is affected by both temperature and precipitation. The specific growth-climate relationships are species dependent. Under the future climate change scenarios, the $P$. koraiensis growth will increase, whereas the L. olgensis and P. jezoensis radial growth will decrease relatively. In consequence, $P$. koraiensis in the higher attitude are more favorable for forestation compared with the other two tree species, and this finding can be used as an important basis of healthy forest management in this region.

\section{DATA AVAILABILITY STATEMENT}

The original contributions presented in the study are included in the article/supplementary material, further inquiries can be directed to the corresponding author.

\section{AUTHOR CONTRIBUTIONS}

HW and WZ were responsible for the research design and the editing coordination of the manuscript, tree-ring width measurement, and contributed in editing and reviewing the manuscript. HW, YN, and CL data preparation and analysis were partitioned as follows: site inventory and sample collection. HW, PX, and WZ tree-ring growth and climate relationship analysis. All authors contributed to the article and approved the submitted version.

\section{FUNDING}

This research was funded by the Fundamental Research Funds of Shandong University (Grant No. 2020GN107).

\section{ACKNOWLEDGMENTS}

We thank Xuemei Shao and Xiuqi Fang for their help in methodology. We also thank Zhiyong Yin, Haifeng Zhu, Li Chen, and Dongsheng Zhao for their help in materials for study. 


\section{REFERENCES}

Breitenmoser, P. D., Brönnimann, S., and Frank, D. (2014). Forward modelling of tree-ring width and comparison with a global network of tree-ring chronologies. Clim. Past. 10, 437-449. doi: 10.5194/cp-10-437-2014

Briffa, K. R., and Jones, P. D. (1990). "Basic chronology statistics and assessment," in Methods of Dendrochronology: Applications in the Environmental Sciences, eds E. R. Cook and L. A. Kairiukstis (Dordrecht: Kluwer Academic Publishers).

Castagneri, D., Nola, P., Motta, R., and Carrer, M. (2014). Summer climate variability over the last 250 years differently affected tree species radial growth in a mesic Fagus-Abies-Picea old-growth forest. For. Ecol. Manag. 320, 21-29. doi: 10.1016/j.foreco.2014.02.023

Chen, L., Huang, J. G., Stadt, K. J., Comeau, P. G., Zhai, L. H., Dawson, A., et al. (2017). Drought explains variation in the radial growth of white spruce in western Canada. Agr. For. Meteorol. 233, 133-142. doi: 10.1016/j.agrformet. 2016.11.012

Cook, E. R. (1985). A Time Series Approach to Tree-ring Standardization. Ph.D. Thesis. Tucson, AZ: University of Arizona.

Cook, E. R., Briffa, K. R., Shiyatov, S. G., and Mazepa, V. S. (1990). "Tree-ring standardization and growth-trend estimation," in Methods of Dendrochronology: Applications in the Environmental Sciences, eds E. R. Cook and L. A. Kairiukstis (Dordrecht: Kluwer Academic Publishers).

Cook, E. R., Woodhouse, C. A., Eakin, C. M., Meko, D. M., and Stahle, D. W. (2004). Long-term aridity changes in the western United States. Science 306, 1015-1018. doi: 10.1126/science. 1102586

Editorial Commission of Northeast Regional Climate Change Assessment Report (2013). Summary for Policymakers and Executive of Northeast Regional Climate Change Assessment Report. Beijing: Meteorological Press.

Editorial Committee for Forestry of Jilin (1988). Forest of Jilin. Beijing: China Forestry Press.

Feliksik, E., and Wilczyński, S. (2009). The effect of climate on tree-ring chronologies of native and nonnative tree species growing under homogenous site conditions. Geochronometria 33, 49-57. doi: 10.2478/v10003-009-0006-4

Fonti, P., and García-González, I. (2004). Suitability of chestnut earlywood vessel chronologies for ecological studies. New Phytol. 163, 77-86. doi: 10.1111/j.14698137.2004.01089.x

Fritts, H. C. (1974). Relationships of ring-widths in arid-site conifers to variations in monthly temperature and precipitation. Ecol. Monogr. 44, 411-440. doi: $10.2307 / 1942448$

Fritts, H. C. (1976). Tree Rings and Climate. London: Academic Press.

Gao, L., Zhang, Y., Wang, X., Zhang, C., Zhao, Y., and Liu, L. (2018). Sensitivity of three dominant tree species from the upper boundary of their forest type to climate change at Changbai Mountain, Northeastern China. Tree Ring Res. 74, 39-49. doi: 10.3959/1536-1098-74.1.39

Graumilch, L. J. (1993). Response of tree growth to climatic variation in the mixed conifer and deciduous forests of the upper Great Lakes region. Can. J. For. Res. 23, 133-143. doi: $10.1139 / \times 93-020$

Han, J. S., Zhao, H. Y., Zhu, L. J., Zhang, Y. D., Li, Z. S., and Wang, X. C. (2019). Comparing the responses of radial growth between Quercus mongolica and Phellodendron amurense to climate change in Xiaoxing'an Mountains, China. Chin. J. Appl. Ecol. 30, 2218-2230. doi: 10.13287/j.1001-9332.201907.012

Holmes, R. L. (1983). Computer-assisted quality control in tree-ring dating and measurement. Tree Ring Bull. 43, 69-78. doi: 10.1006/biol.1999.0214

Housset, J. M., Nadeau, S., Isabel, N., Depardieu, C., Duchesne, I., Lenz, P., et al. (2018). Tree rings provide a new class of phenotypes for genetic associations that foster insights into adaptation of conifers to climate change. New Phytol. 218, 630-645. doi: 10.1111/nph.14968

Hughes, M. K. (2002). Dendrochronology in climatology-the state of the art. Dendrochronologia 20, 95-116. doi: 10.1078/1125-7865-00011

IPCC (2013). Climate Change 2013: The Physical Science Basis. Contribution of Working Group I to the Fourth Assessment Report of the Intergovernmental Panel on Climate Change. Cambridge: Cambridge University Press.

Jia, X., Jin, H., Zhao, Y., Yin, H., Liu, L. J., Wang, C., et al. (2017). Characteristics of climate change in Changbai Mountain from 1958 to 2015. J. Beihua Univ. (Nat. Sci.) 18, 727-731. doi: 10.11713/j.issn.1009-4822.2017.06.005

Jiang, Y. G., Yuan, X., Zhang, J. H., Han, S. J., Chen, Z. J., Wang, X. G., et al. (2019). Reconstruction of June-July temperatures based on a 233 year tree-ring of Picea jezoensis var. microsperma. Forests 10:416. doi: 10.3390/f10050416
Lebourgeois, F., Mérian, P., Courdier, F., Ladier, J., and Dreyfus, P. (2012). Instability of climate signal in tree-ring width in Mediterranean mountains: a multi-species analysis. Trees 26, 715-729. doi: 10.1007/s00468-011-0 638-7

Li, G. Q., Bai, F., and Sang, W. G. (2011). Different responses of radial growth to climate warming in Pinus koraiensis and Picea jezoensis var.komarovii at their upper elevational limits in Changbai Mountain. Chin. J. Appl. Ecol. 35, 500-511. doi: 10.3724/SP.J.1258.2011.00500

Liang, E. Y., Shao, X. M., Eckstein, D., and Liu, X. H. (2010). Spatial variability of tree growth along a latitudinal transect in the Qilian Mountains, northeastern Tibetan Plateau. Can. J. For. Res. 40, 200-211. doi: 10.1139/X09-186

Lindner, M., Maroschek, M., Netherer, S., Kremer, A., Barbati, A., Garcia-Gonzalo, J., et al. (2010). Climate change impacts, adaptive capacity, and vulnerability of European forest ecosystems. For. Ecol. Manag. 259, 698-709. doi: 10.1016/j. foreco.2009.09.023

Moss, R. H., Edmonds, J. A., Hibbard, K. A., Manning, M. R., Rose, S. K., van Vuuren, D. P., et al. (2010). The next generation of scenarios for climate change research and assessment. Nature 463, 747-756. doi: 10.1038/Nature0 8823

Pederson, N., Cook, E. R., Jacoby, G. C., Peteet, D. M., and Griffin, K. L. (2004). The influence of winter temperatures on the annual radial growth of six northern range margin tree species. Dendrochronologica 22, 7-29. doi: 10.1016/j.dendro. 2004.09.005

Prislan, P., Grièar, J., Ėufar, K., Luis, M., Merela, M., and Rossi, S. (2019). Growing season and radial growth predicted for Fagus sylvatica under climate change. Clim. Chang. 153, 181-197. doi: 10.1007/s10584-019-02374-0

Rahman, M., Islam, R., and Islam, M. (2017). Long-term growth decline in Toona ciliata in a moist tropical forest in Bangladesh: impact of global warming. Acta Oecol. 80, 8-17. doi: 10.1016/j.actao.2017.02.004

Russell, A. E., and Parton, W. J. (2020). Modeling the effects of global change on ecosystem processes in a tropical rainforest. Forests 11:213. doi: 10.3390/ f11020213

Schweingruber, F. H. (1988). Tree Rings: Basics and Applications of Dendrochronology. Dordrecht: Kluwer Press.

Schweingruber, F. H., Briffa, K. R., and Nogler, P. (1993). A tree-ring densitometric transect from Alaska to Labrador. Int. J. Biometeorol. 37, 151-169. doi: 10.1007/ BF01212625

Shao, X. X., Fang, X. Q., Liu, H. B., and Huang, L. (2003). Dating the 1000-year-old Qilian Juniper in Mountains along the Eastern Margin of the Qaidam Basin. Acta Geogr. Sin. 58, 90-100. doi: 10.11821/xb200301011

Shen, C. C., Wang, L. L., and Li, M. Y. (2016). The altitudinal variability and temporal instability of the climate-tree-ring growth relationships for Changbai larch (Larix olgensis Henry) in the Changbai mountains area, Jilin, Northeastern China. Trees 30, 901-912. doi: 10.1007/s00468-015-1330-0

Stokes, M. A., and Smiley, T. L. (1968). An Introduction to Tree-Ring Dating. Chicago, IL: University of Chicago Press.

Wang, H., Shao, X. M., Jiang, Y., Fang, X. Q., and Wu, S. H. (2013). The impacts of climate change on the radial growth of Pinus koraiensis along elevations of Changbai mountain in northeastern China. For. Ecol. Manag. 289, 333-340. doi: 10.1016/j.foreco.2012.10.023

Wang, H., Shao, X. X., Fang, X. Q., Jiang, Y., Liu, C. L., and Qiao, Q. (2017). Relationships between tree-ring cell features of Pinus koraiensis and climate factors in the Changbai Mountains, Northeastern China. J. For. Res. 28, 105114. doi: 10.1007/s11676-016-0292-4

Wang, L., Wang, W. J., Wu, Z., Du, H., Zong, S., and Ma, S. (2019). Potential distribution shifts of plant species under climate change in Changbai Mountains, China. Forests 10:498. doi: 10.3390/f10060498

Wang, S. P., Wang, Z. H., Piao, S. L., and Fang, J. Y. (2010). Regional differences in the timing of recent air warming during the past four decades in China. Chin. Sci. Bull. 55, 1968-1973. doi: 10.1007/11434-010-3236-y

Wang, X. C., Zhang, M. H., Ji, Y., Li, Z. S., Li, M., and Zhang, Y. D. (2017). Temperature signals in tree-ring width and divergent growth of Korean pine response to recent climate warming in northeast Asia. Trees 31, 415-427. doi: 10.1007/s00468-015-1341-x

Wigley, T. M. L., Briffa, K. R., and Jones, P. D. (1984). On the average value of correlated time series, with applications in dendroclimatology and hydrometeorology. J. Appl. Meteorol. Clim. 23, 201-213. doi: 10.1175/1520045019840232.0.CO;2 
Wimmer, R., and Grabner, M. (2000). A comparison of tree-ring features in Picea abies as correlated with climate. IAWA J. 12, 403-416. doi: 10.1163/2294193290000256

Wu, Y. L., Gan, M., and Yu, R. D. (2019). Effect of climate on the radial growth of Larix sibirica and its phenological features in the eastern Tianshan Mountains. Chin. J. Appl. Environ. Biol. 25, 1301-1311. doi: 10.19675/j.cnki.1006-687x. 2018.12035

Xu, J. W., Xu, M., Jiang, X., Remedio, A. R. C., Sein, D. V., Koldunov, N., et al. (2016). The assessment of surface air temperature and precipitation simulated by regional climate model REMO over China. Adv. Clim. Chang. Res. 12, 286-293. doi: 10.12006/j.issn.1673-1719.2015.194

Xu, Y. L., Zhang, Y., Lin, E. D., Lin, W. T., Dong, W. J., Jones, R., et al. (2006). Analyses on the climate change responses over China under SRES B2 scenario using PRECIS. Chin. Sci. Bull. 51, 2260-2267. doi: 10.1007/s11434-006-2099-8

Yan, B. Q., Lin, W. Z., Liu, Q. J., and Yu, J. (2017). Age-dependent radial growth responses of Larix chinensis to climatic factors in Qinling Mountains, northwestern China. J. Beijing For. Univ. 39, 58-65. doi: 10.13332/j.1000-1522. 20170161

Yin, Y. H., Ma, D. Y., Wu, S. H., and Pan, T. (2015). Projections of aridity and its regional variability over China in the mid-21st century. Int. J. Clim. 35, 4387-4398. doi: 10.1002/joc.4295

Yu, D. P., Wang, Q. L., Wang, G. G., and Dai, L. M. (2006). Dendroclimatic response of Picea jezoensis along an altitudinal gradient in Changbai Mountains. Sci. China Ser. E 49, 150-159. doi: 10.1007/s11434-006-8116-0

Yu, D. P., Wang, Q. W., Wang, Y., Zhou, W. M., Ding, H., Fang, X. M., et al. (2011). Climatic effects on radial growth of major tree species on Changbai Mountain. Ann. For. Sci. 68, 921-933. doi: 10.1007/s13595-011-0098-7

Yu, J., Chen, J. J., Meng, S. W., Zhou, H., Zhou, G., Gao, L. S., et al. (2021). Response of radial growth of Pinus sylvestriformis and Picea jezoensis to climate warming in the ecotone of Changbai Mountain, Northeast China. Chin. J. Appl. Ecol. 32, 46-56. doi: 10.13287/j.1001-9332.202101.004

Yu, J., Luo, C. W., Xu, Q. Q., Meng, S. W., Li, J. Q., and Liu, Q. J. (2016). Radial growth of Pinus koraiensis and carbon sequestration potential of the old growth forest in Changbai Mountain. Northeast China. Acta Ecol. Sin. 36, 2626-2636. doi: $10.5846 /$ stxb201411152263
Yu, X. J., Liu, Y. Y., Du, Y. D., and Wei, X. L. (2015). Projection of climate change in Changbai Mountain under RCPs scenarios. J. Meteorol. Environ. 31, 65-73. doi: 10.3969/j.issn.1673-503X.2015.04.010

Zeng, X. F., Li, Q. P., Su, B. D., Liu, Y. L., and Chen, H. (2009). Change and projection of climate in the Songhua River Basin. Adv. Clim. Chang. Res. 5, 215-219. doi: 10.3969/j.issn.1673-1719.2009.04.005

Zhang, L. N., Jiang, Y., Zhao, S. D., Jiao, L., and Wen, Y. (2018). Relationships between tree age and climate sensitivity of radial growth in different drought conditions of Qilian Mountains, northwestern China. Forests 9:135. doi: 10 3390/f9030135

Zhang, X. Z., Li, X. X., Xu, X. C., and Zhang, L. J. (2017). Ensemble projection of climate change scenarios of China in the 21st century based on the preferred climate models. Acta Geogr. Sin. 72, 1555-1568. doi: 10.11821/dlxb20170 9002

Zhuang, L., Axmacher, J. C., and Sang, W. G. (2017). Different radial growth responses to climate warming by two dominant tree species at their upper altitudinal limit on Changbai Mountain. J. For. Res. 28, 795-804. doi: 10.1007/ s11676-016-0364-5

Conflict of Interest: The authors declare that the research was conducted in the absence of any commercial or financial relationships that could be construed as a potential conflict of interest.

Publisher's Note: All claims expressed in this article are solely those of the authors and do not necessarily represent those of their affiliated organizations, or those of the publisher, the editors and the reviewers. Any product that may be evaluated in this article, or claim that may be made by its manufacturer, is not guaranteed or endorsed by the publisher.

Copyright (c) 2022 Wang, Ning, Liu, Xu and Zhang. This is an open-access article distributed under the terms of the Creative Commons Attribution License (CC BY).

The use, distribution or reproduction in other forums is permitted, provided the original author(s) and the copyright owner(s) are credited and that the original publication in this journal is cited, in accordance with accepted academic practice. No use, distribution or reproduction is permitted which does not comply with these terms. 